\title{
LA PRODUCCIÓN DE PODER EN EL ENTORNO CONSTRUIDO A TRAVÉS de la invasión española, valle del Colca (Perú)
}

\author{
Steven A. Wernke ${ }^{\text {a }}$
}

\begin{abstract}
Resumen
El entorno construido desempeñó un rol central en las politicas dirigidas a construir una nueva sociedad andina colonial. Los españoles se acercaron al urbanismo como una precondición y el generador de la comunidad civica. Desde precedentes en el mundo mediterráneo, la escenificación de lo espectacular fue esencial para el diseño y construcción del espacio urbano español, especialmente a través de las formas de la plaza y la iglesia. Tales asociaciones y formas tienen analogías en los Andes prehispánicos tardios, y en la politica colonial de Tawantinsuyu en particular. En este articulo, se reproduce cómo estas formas, ideologias y prácticas espaciales se ensamblaron a través de la invasión española, con un enfoque en la (re) construcción y (re) uso de espacios rituales en el contexto del valle del Colca (sierra suroeste del Perú). En particular, se analiza cómo la configuración de kallanka/pata se tradujo a iglesialplaza desde la primera evangelización en doctrinas franciscanas hasta la reducción general de indios del virrey Toledo. Esta exploración demuestra una larga y marcada trayectoria de procesos y eventos centrípetos desde la época inkaica hasta la reducción, y la centralidad de tales espacios rituales. Lo que surge es una visión de apropiación mutua, más que de dominación a través de un urbanismo compulsivo.
\end{abstract}

Palabras clave: entorno construido, urbanismo, reducción, arquitectura, análisis espacial

\section{Abstract \\ PRODUCTION OF POWER IN THE BUILT ENVIRONMENT DURING THE SPANISH INVASION, COLCA VALLEY (PERU)}

The built environment played a central role in policies intended to build a new colonial Andean society. The Spanish approached urbanism as a precondition and generator of the civic community. From precedents in the Mediterranean world, the staging of spectacle was integral to the design and construction of Spanish urban space, especially through the forms of the plaza and the church. Such associations and forms have analogies in the late prehispanic Andes, and in the colonial policies of Tawantinsuyu in particular. This paper traces out how these spatial forms, ideologies, and practices articulated through the Spanish invasion, with a focus on the (re)construction and (re) use of ritual spaces in the context of the Colca Valley (southwestern highlands of Peru). Specifically, analysis of how the configuration of kallankalpata translated to church/plaza since the first evangelization in Franciscan doctrinal settlements, through the general resettlement of Indians (reducción general de indios) under the Viceroy Francisco de Toledo. This exploration reveals a long and punctuated trajectory of centripetal processes and events from the Inka era through the reduccion, and the centrality of these ritual spaces in them. What emerges is a picture of mutual appropriation more than domination through compulsory urbanism.

Keywords: built environment, urbanism, reducción, architecture, spatial analysis

${ }^{a}$ Departamento de Antropología, Vanderbilt University

Correo electrónico: s.wernke@vanderbilt.edu 


\section{Introducción}

El entorno construido constituyó uno de los medios primarios por los cuales la sociedad colonial andina y sus relaciones de poder fueron producidas. Los invasores españoles predicaron su proyecto colonial en el virreinato del Perú con una teoría bastante determinista del rol del entorno construido. Desde las reformas recomendadas por Juan de Matienzo y (parcialmente), ejecutadas por el virrey Francisco de Toledo, la intención de fundar pueblos de indios cuadriculados y centrados por iglesias pretendía no solamente reflejar el nuevo orden social colonial, sino generarlo. La gran preocupación de construir (en el sentido literal) el orden colonial se refleja tanto en los inmensos esfuerzos dedicados a erigir los monumentos y espacios urbanos en las Américas, como en el gran corpus de investigaciones dirigidas a entenderlos. Sin embargo, también, la mayoría de los trabajos de este corpus, proveniente mayormente de las disciplinas de Historia, Historia de Arte y Arquitectura, se han enfocado en cuestiones de orígenes de formas y estilos; en el cambio, mixtura o convergencia de estilos arquitectónicos e iconográficos; y, en menor cuantía, en el sentido de los nuevos entornos construidos. Mucho menos se han investigado (y como otros autores han notado en este volumen, aún menos en los Andes) los procesos involucrados en su mismo emplazamiento, construcción y uso del entorno construido.

Este ensayo se acerca a esta problemática a través de un análisis de la trayectoria histórica local entre la época transicional inkaica-colonial hasta la fundación y construcción de las reducciones toledanas durante la década de 1570 en el valle del Colca, ubicada en la vertiente occidental de los Andes sur-centrales (departamento de Arequipa, Perú).

\section{Produciendo espectáculo: urbanismo inkaico y español}

En este artículo, se consideran en particular los aspectos performativos del entorno construido a través de la invasión española: la manipulación y el uso participativo de los espacios públicos. Concretamente, se enfoca en los espacios de rituales o ceremonias participativas - producciones culturales espectaculares - tanto en el contexto de las relaciones entre poblaciones locales y el estado inkaico como en la producción de nuevas subjetividades y un nuevo orden social después de la invasión española.

La noción de la ciudad como escenario para el espectáculo tiene raíces profundas en el mundo mediterráneo (Bell 2006). No obstante, en los Andes, el urbanismo parece aún más ligado al ceremonialismo que a los centros orgánicos de residencia e intercambio que desarrollaron en el mundo mediterráneo. De hecho, las evidencias son cada vez más convincentes sobre el enlace íntimo entre el ceremonialismo y el urbanismo, a través de la trayectoria prehispánica y diversas regiones de los Andes (Makowski 2003). En cuanto al urbanismo de los inkas, Craig Morris, quizás más que cualquier otro investigador de su generación, abrió una visión del Tawantinsuyu como un Estado teatral y demostró la centralidad de la escenificación de ceremonias públicas en el diseño de los centros imperiales (Morris 2013, 1982, 1973, 1970; Morris y Thompson 1985). Desde esos estudios pioneros, los aspectos teatrales parecen cada vez más céntricos del reinado inkaico y esta perspectiva ha sido atendida por un número creciente de investigadores (v.g. Bray 2003; Dillehay 2003; Ramírez 2005; Coben 2006). Los ritos escenificados en las plazas centrales crearon marcos paradigmáticos de las relaciones entre el Estado y sus sujetos; el emperador se presentó como ancestro-deidad, centro cosmológico y proveedor-padre para sus «hijos» (Ramírez 2005). A su vez, este manejo de la representación y producción de «dominación» depende de la ética y el ethos de su antítesis: lo comunitario. Los ritos centrales en las provincias del inkanato representaron a la figura del inka como una extensión de la figura del kuraka y las demandas extractivas del Estado funcionaban como una extensión de las obligaciones recíprocas del ayllu (Silverblatt 1988). Este dilema del poder en el inkanato no fue (y a lo mejor, jamás habría sido) resuelto, a la vez que regulaba las relaciones entre las comunidades locales y los agentes e instituciones españoles. El «pacto de reciprocidad» llegó a definir la política entre las comunidades andinas y las instituciones coloniales 
(Gose 2008). En pocas palabras, fue la manera a partir de la cual el pueblo andino logró asimilar el clero, los encomenderos y los magistrados a su política.

Bell (2006: 5-6), en el contexto mediterráneo, plantea una observación similar:

Ningún régimen puede existir cómodamente sin proporcionar por lo menos un semblante simbólico de su popularidad o por lo menos su derecho a deferencia. Las relaciones que componen obvias asimetrías de poder siempre requieren, al parecer, una articulación ritual en la presencia de una audiencia; y una audiencia de sujetos políticos siempre tiene la potencia de transformar, o a veces hasta rechazar esas relaciones (traducción por el autor). ${ }^{1}$

El espectáculo, entonces, no necesariamente produce el arreglo de poder concebido por la élite, debido a la misma necesidad de alinear su producción con ideologías, prácticas y experiencias populares. Esta problemática se intensifica en situaciones coloniales, en las cuales no se comparten las ontologías, ideologías y lógicas entre el colonizador y el colonizado. Los arquitectos del sistema virreinal del Perú reconocían los riesgos de la estabilidad; de hecho, se aprecian cada vez más las maneras sutiles de la naturaleza conservadora de no solamente la primera evangelización (Estenssoro 2003), sino también de las mismas reformas toledanas (Mumford 2012). Como Jeremy Mumford lo articula en su libro reciente, «mientras Toledo ordenaba en voz alta la transformación, a grandes rasgos, del modo andino de organizar el espacio, silenciosamente preservaba sus detalles» (Mumford 2012: 116).

Mientras que Mumford hábilmente recupera indicios de estas sutiles dimensiones etnográficas en los textos coloniales, en este ensayo, se persigue estas dimensiones etnográficas del colonialismo español en los Andes, a través de sus medios primarios: los del entorno construido. Tal análisis requiere una perspectiva situada y local para ver de manera tangible la secuencia de manipulación del espacio a través de la incorporación imperial inkaica, la invasión española, y el establecimiento de los fundamentos del sistema de asentamiento poshispánico. Se ubica el análisis en el valle del Colca, lugar de investigaciones de largo plazo por el autor.

\section{Kallankas, iglesias y plazas: modelos espaciales analógicos}

¿Dónde —en cuáles espacios específicos - fueron negociadas tales lógicas y prácticas espaciales? Aunque son múltiples e interrelacionadas, aquí se enfocará en lo que constituyeron complejas analogías en la construcción del orden urbano y la escenificación del espectáculo urbano inkaico y español: kallanka/pata e iglesia/plaza.

La centralidad de plazas rodeadas por edificios ceremoniales alargados, de una habitación con múltiples puertas trapezoidales (referidos como kallanka en la literatura) está bien documentada y es conocida. Servían como escenarios para la elaboración de procesiones coreografiadas y ritos comensales, que manifestaban una ideología de beneficencia estatal a través de la redistribución conspicua de bienes suntuosos y de consumo; así, se reciprocaba (de manera asimétrica) la fidelidad y servicios laborales de las poblaciones bajo dominio.

De semejante manera, por lo menos a nivel de aparejos externos, un espacio con características de una plaza junto y un templo (capilla o iglesia) constituyeron los escenarios centrales de los rituales católicos desde los primeros complejos evangélicos en las Américas. El modelo estándar franciscano que se desarrolló mandaba que la iglesia se oriente al eje tradicional este-oeste, con el convento adjunto (idealmente, hacia el sur), y enfrentado por un atrio y portería. El atrio —o más precisamente de acuerdo a la nomenclatura de los frailes, el corral (así se aludía a la función del fraile como pastor de su rebaño, ver Lara 2004) — debía ser amurallado. Se adjuntó una capilla abierta a la fachada de la iglesia, desde donde se dirigieron una variedad de actividades rituales en el corral. En las cuatro esquinas del corral, se acomodaron pequeńas capillas llamadas "posas» (derivado de posar, que refiere a su función como puntos de pausa en las procesiones que se realizaron en el atrio); y en el centro, una cruz (Toussaint 1967). El foco de actividad fue el atrio, según los mismos frailes, quienes relatan su uso para los días sagrados, cuando las grandes congregaciones 
no encajaron en la iglesia (Schuetz-Miller 2000). Sin embargo, la centralidad del corral no se debe solamente a tales necesidades, sino también a la improvisación de catolicismo en las prácticas religiosas indígenas, las cuales no se centraban en la recitación de una doctrina de fe, sino en la participación en rituales públicos.

Como ilustra Burkhart en una serie de estudios sobre la adaptación del catolicismo a las prácticas de grupos nahuas, el atrio asumió importancia central por su función analógica como escenario para desfiles y otros espectáculos de las prácticas indígenas (Burkhart 1991, 1996, 1998). De esta manera, ciertos aspectos rituales-participativos del catolicismo - especialmente, las procesiones y el uso de la música - fueron amplificados; y sus formas, sutilmente transformadas en su apropiación por las poblaciones nahuas.

En los Andes, se está abriendo una visión similar. La primera evangelización se caracterizó por prácticas pastorales experimentales y flexibles con énfasis en participación litúrgica a través de medios no-verbales, como la música y las procesiones (Estenssoro 2003, 2001). La sacramentación y la instrucción doctrinal fueron mínimas hasta después de las reformas del Segundo y Tercer Concilio Limense. Aún después de las reformas, el breviario más utilizado - Symbolo catholico indiano del notable franciscano Luis Jerónimo de Oré- se centró en siete cánticos en quechua, que narraron la historia sagrada (desde la creación hasta la fundación de la iglesia católica, una parte para cada día de la semana). La intención fue cantar los himnos en procesión por los pueblos de indios (reducciones) como parte de las horas canónicas (Durston 2007: 147). Es de notar que hay una conexión histórica directa entre este breviario cuasioficial y el contexto específico de este ensayo. Oré fue uno de los frailes principales residentes en el valle del Colca durante los ańos inmediatamente antes de la publicación del Symbolo catholico indiano (Cook 2002). Casi seguramente elaboró, por lo menos, una parte de este programa durante sus días en el pueblo de Coporaque (ubicado en la parte central del valle del Colca).

Los elementos arquitectónicos que acomodaron y escenificaron la evangelización en los Andes también parecen coherentes con estas prácticas. La predominancia de la forma de la capilla abierta en los complejos tempranos parece diseñada en parte para acomodar la catequesis al aire libre, frente a congregaciones grandes en los atrios o plazas asociados (Gisbert y Mesa 1985). La misma iglesia de Coporaque es uno de los únicos ejemplares originales de esta forma todavía conservada en el Perú (Tord 1983; Gutiérrez et al. 1986). Sin embargo, como se ha presentado en otras publicaciones, nuestros estudios arqueológicos han documentado una serie de capillas rústicas antecedentes a este tipo de templo. Abajo se presenta un resumen del contexto histórico de la misión franciscana temprana en el Colca y sus complejos arquitectónicos correspondientes.

\section{Las doctrinas de los collaguas}

Después de la invasión española del Tawantinsuyu, el valle del Colca, el valle más grande de la cordillera occidental del sur del Perú, fue uno de los lugares más tempranos de evangelización por el orden franciscano. Esta intervención temprana parece deberse a la importancia económica y política regional del valle y sus habitantes: los grupos étnicos collaguas y los cabanas. Con una población combinada de unos 70.000 habitantes durante fines de la época prehispánica, los cabanas (quechuahablantes) ocuparon la parte baja; y los collaguas (aimarahablantes), las partes centrales y altas del valle (Galdos Rodríguez 1984; Málaga Medina 1977; Pease 1977) (Fig. 1).

Es probable que los franciscanos iniciaran sus actividades entre los collaguas durante la década de 1540 a la invitación de los encomenderos (Tibesar 1953: 65). No se ha ubicado documentación contemporánea con la entrada de los frailes al valle, pero un memorial escrito en 1585 recuenta la llegada de un grupo encabezado por fray Juan de Monzón y Juan de Chaves 40 años antes -en 1545 aproximadamente (AFSL registro 15, parte 5)-.

Con el apoyo del segundo virrey La Gasca y el nuevo encomendero Francisco Noguerol de Ulloa, los franciscanos expandieron y formalizaron sus doctrinas en el valle después de la derrota de las fuerzas de Gonzalo en 1548. En 1560, Villacarrillo asignó cuatro frailes más a las doctrinas 


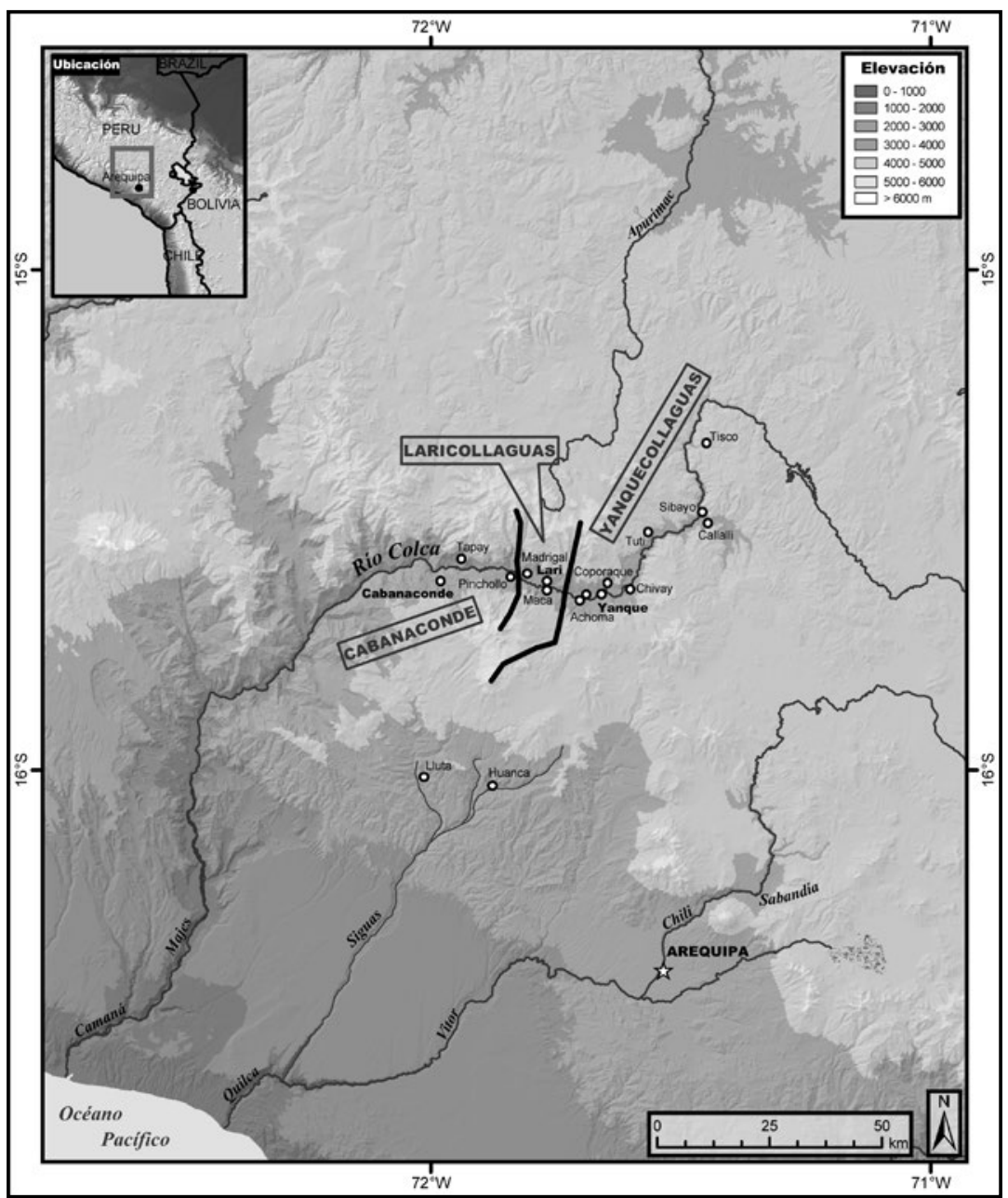

Figura 1. El valle del Colca en el entorno regional, mostrando sus divisiones territoriales.

de los collaguas, quienes establecieron el convento de la Concepción Inmaculada en Yanque y otro convento en Callalli (en la parte alta del valle) (Córdoba y Salinas 1957 [1651]: 151-167). Esta época coincide con el comienzo de políticas más centralizadoras y ortodoxas, ambos a nivel global con la Contrarreforma y, a nivel regional, con la reacción contra el taqui onqoy, la promulgación del segundo Concilio Limense, y la llegada de los decretos doctrinales del Concilio de Trento a Lima a mediados de la década de 1560.

La congregación de poblaciones a las doctrinas se intensificó durante esta época. Como en otros locales (Málaga Medina 1974), los frailes empezaron a experimentar con la consolidación poblacional en Yanquecollaguas. Por ejemplo, un pasaje de la Memoria de la Santa Iglesia de Arequipa por Echeverría y Morales especifica que los frailes congregaron pobladores de varios ayllus a una doctrina con el nombre original de "Cupi» ${ }^{2}$. A través de varias líneas de evidencia, se puede afirmar que esta doctrina corresponde al sitio conocido como San Antonio en la actualidad, uno de los asentamientos principales de la zona de Coporaque durante la época inkaica (Wernke 2007a, 2007b, 2013b). 


\section{El emplazamiento y organización de las doctrinas tempranas}

Previa prospección arqueológica en la zona de Yanque y Coporaque (el área del núcleo político de Yanquecollaguas), por el autor, se han documentado cuatro capillas rústicas en asentamientos con arquitectura administrativa inkaica, los cuales corresponden a cuatro de las doctrinas tempranas descritas en las fuentes documentales. Dos de estas capillas están situadas en dos de las aldeas más grandes del Intermedio Tardío en la zona de prospección, las cuales se convirtieron a centros administrativos secundarios durante la ocupación inkaica: Uyu Uyu (YA-050) y San Antonio (CO-100) (Fig. 2). Estos sitios fueron abandonados a la fuerza con la fundación de las reducciones. Los de Uyu Uyu fueron desplazados a Yanque, en la otra vertiente del río Colca, mientras los de San Antonio fueron desplazados a Coporaque. Ambos, Coporaque y Yanque, también fueron locales de doctrinas prereduccionales. La capilla de San Sebastián en Coporaque fue construida alrededor de 1565 y, después, fue integrada al complejo parroquial como una capilla miserere (Tord 1983). La iglesia principal de la reducción de Coporaque (la iglesia de Santiago de Coporaque) es el único ejemplar original entre las iglesias reduccionales en el valle y entre muy pocas en todo el Perú (Tord 1983). En Yanque, la iglesia y el convento han sido modificados varias veces después de daños ocasionados por terremotos (la mayoría de las estructuras actuales datan de los años después del terremoto de 1688; al respecto se puede consultar Benavides 1994); por eso, no se han identificado restos de una capilla temprana dentro del complejo. No obstante, nuestra prospección ha identificado una capilla de forma y estilo similar a los ejemplares de Uyu Uyu, San Antonio y Coporaque en una manzana al oeste de la reducción (Wernke 2007a). La distribución de elementos arquitectónicos (bloques finamente trabajados al estilo inka imperial) y prevalencia de cerámica inka polícromo dentro de un área grande (18 hectáreas) de la reducción de Yanque señala cómo la reducción se fundó en el mismo lugar del centro administrativo inkaico principal (Wernke 2006, 2009). A nivel de patrón de asentamiento, entonces, la marcada continuidad entre los centros administrativos inkaicos y los centros de evangelización temprana indican claramente cómo los frailes reconocieron e injertaron sus doctrinas a nodos políticos de la época inkaica (Wernke 2007a).

A nivel de la organización espacial de estas doctrinas, es particularmente llamativa la misma prominencia visual de las capillas, y cómo las capillas y sus atrios (o corrales) fueron ubicados en estrecha proximidad con las plazas y kallankas inkaicas. En Uyu Uyu, la capilla — una estructura rústica de una nave rectangular simple y una plataforma de altar hacia el este- da directamente a la plaza inkaica, al lado opuesto a la kallanka, que ocupa todo el lado oeste de la plaza. En San Antonio, la capilla se rodea por un atrio circular y amurallado encima de un promontorio frente a la zona residencial principal en las laderas circundantes. En este caso, la kallanka (de similares dimensiones que el ejemplar de Uyu Uyu) y su plaza asociada están adyacentes al área de la capilla y su atrio, que ocupan el área entre el promontorio y la zona residencial.

En ambos casos, entonces, las capillas y sus atrios están visualmente prominentes y estrechamente asociados con sus contrapartes analógicos inkaicos. Tales asociaciones entre los complejos evangélicos y espacios ceremoniales-cívicos, como se ha argumentado en más detalle en otras publicaciones, sugieren que los esfuerzos pastorales de los frailes movilizaron analogías de prácticas espaciales para inculcar el catolicismo (Wernke 2007a). Como se explora a continuación, se puede apreciar cómo estos procesos de negociación espacial y transformación mutua tomaron forma, y se desarrollaron a través del tiempo, lo cual será analizado a una escala espacial más nítida dentro de la doctrina de Malata.

\section{Transformaciones espaciales en la doctrina de Malata}

El sitio de Malata se ubica a 3840 metros en la parte alta del valle. La aldea, compuesta por 81 estructuras dentro de un núcleo habitacional de 1,6 hectáreas, ocupa una leve quebrada en una formación de colinas (de origen volcánico) encima de la garganta del río Colca (Figs. 2 y 3). Malata figuró como una aldea pequeña y probablemente funcionaba como una doctrina secundaria; no fue el local de un convento. El fraile habría venido como parte de sus rotaciones pastorales. 


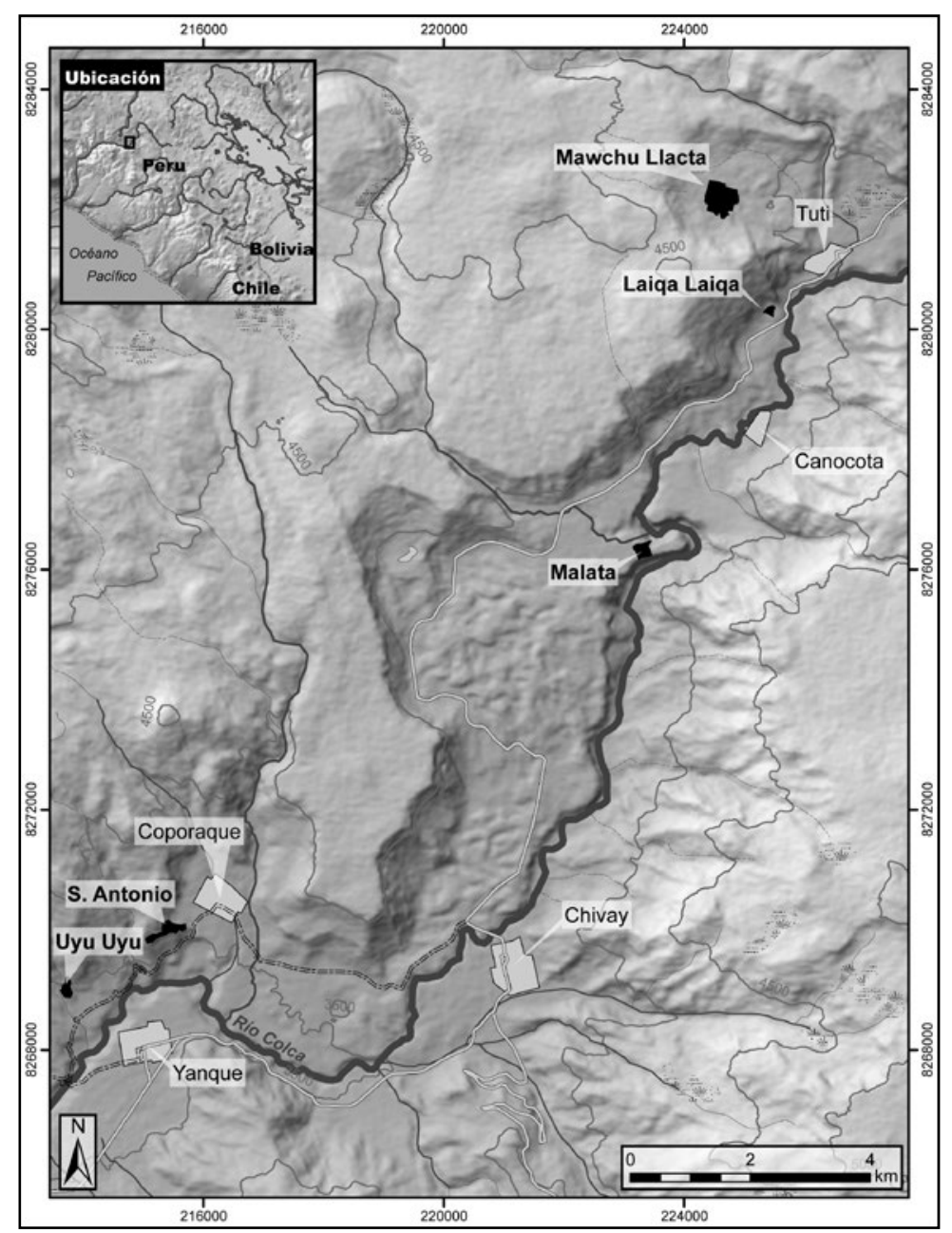

Figura 2. Parte alta del valle del Colca, mostrando los asentamientos mencionados en el texto.

Como el ejemplar mejor preservado de las doctrinas del valle, ofrece un contexto ideal para la investigación de prácticas rituales y domésticas durante la transición entre dominio inkaico y español.

$\mathrm{Al}$ igual que las demás doctrinas del valle, existen espacios arquitectónicos inkaicos y españoles en proximidad: en el extremo oeste del sitio, una kallanka y su plaza asociada se sitúa encima de una terraza alta (Fig. 3). Adyacente hacia el sur de este complejo, se ubica una capilla y atrio frente a una plaza rústica, con una plataforma circular en el centro. Esta configuración no es original, sino que es producto de remodelación significativa. Nuestras excavaciones expusieron que la entrada de la capilla originalmente tuvo cuatro peldaños a partir de la ladera natural y dos de estos peldaños fueron enterrados cuando se construyó el atrio durante un evento de formalización del complejo. El muro de contención para este relleno define el lado oeste de la plaza. Una escalera fue construida desde la plaza para subir al atrio y los dos peldańos superiores de la escalera original dieron acceso a la entrada de la capilla. Mirando hacia afuera desde la entrada de la capilla, se ve la plaza y la zona residencial principal abajo. La plaza, de forma irregular (conformada por los contornos de la quebrada), se define por el muro de contención del atrio y por muros bajos de piedras de campo, con una sola entrada demarcada en su lado este (hacia la zona residencial). Una plataforma circular en el centro servía como peańa para una cruz. Una estructura colonial grande (Estructura 15) ocupa 


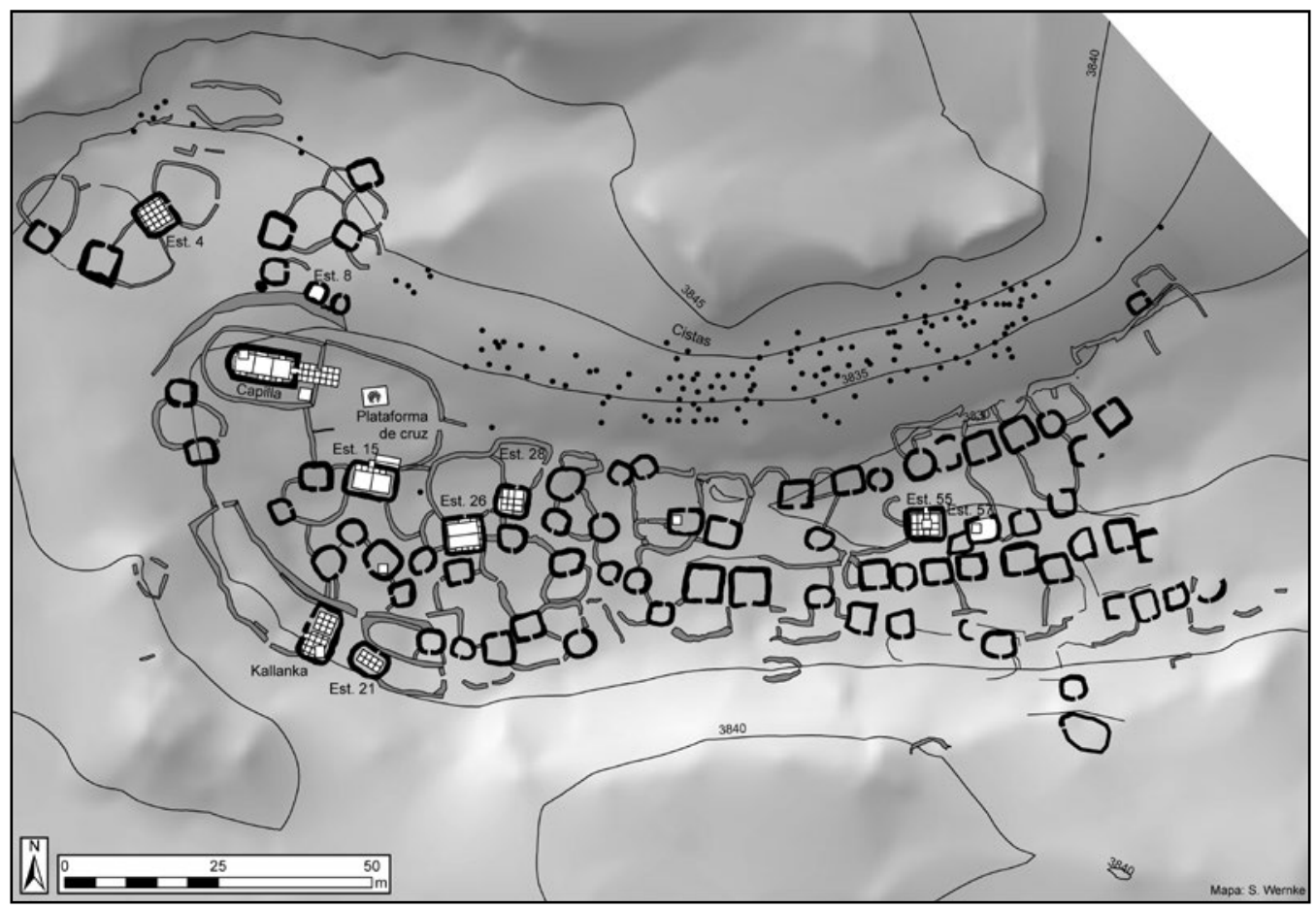

Figura 3. Plano arquitectónico de Malata, indicando las áreas excavadas.

el centro del lado sur de la plaza. Su contexto, forma y ensamble de artefactos indican claramente que esta estructura no fue doméstica, sino de naturaleza pública, a lo mejor para fines de coordinación administrativas o religiosas (Wernke 2011, 2013a). Las entradas de la plaza, de la estructura pública y de la capilla se alinean con la cruz central. A partir de ello, es evidente que el atrio y su articulación espacial con la plaza se completaron durante un evento después de la construcción inicial de la capilla. De esta manera, muestra el desarrollo de un plan de formalización durante la ocupación corta de la doctrina, es decir, entre las décadas de 1540 y 1560.

La prominencia visual de los complejos rituales en Malata se puede comparar a través de una simulación de visibilidad (viewshed). Mientras que este tipo de análisis es relativamente común a la escala de paisaje, poco se lo ha aplicado a nivel intrasitio ( $c f$. Kosiba y Bauer 2012). Para esta simulación, se estimó la altura de las estructuras domésticas a 2,5 metros (una aproximación razonable sobre la base de las alturas promedio de las estructuras preservadas hasta su altura máxima). La capilla, la kallanka, la estructura pública en la plaza (estructura 15) y la casa grande adyacente a esta última (estructura 26) se modelaron con alturas de 3 metros de acuerdo a su tamaño y altura. Los muros que definen los grupos domésticos y otros espacios externos fueron simulados con alturas de 0,50 metros. Se convirtieron en los vectores de la arquitectura a un modelo digital de elevación (MDE) con estos valores y se sumó este MDE con el MDE de la topografía. Sobre esta base, se modeló visibilidad intrasitio con observadores ubicados en los vanos de acceso de cada estructura (en los casos observables; $\mathrm{n}=76$ ), con una altura del observador a 1,5 metros. El resultado se presenta como un raster de visibilidad acumulativa: el valor de cada celda (de una resolución de 0,97 $\mathrm{m}$ ) representa el número de observadores en ese local, de acuerdo con los contornos del paisaje y las alturas de las estructuras. Los resultados se presentan en una escala de grises. El rango de valores de las celdas en el raster abarca de 0 a 72 observadores (Fig. 4).

Los resultados señalan cómo las dos plazas — la plaza inkaica y la colonial—fueron las más visibles entre los espacios construidos del sitio (Fig. 4). Es evidente que la prominencia visual figuraba 


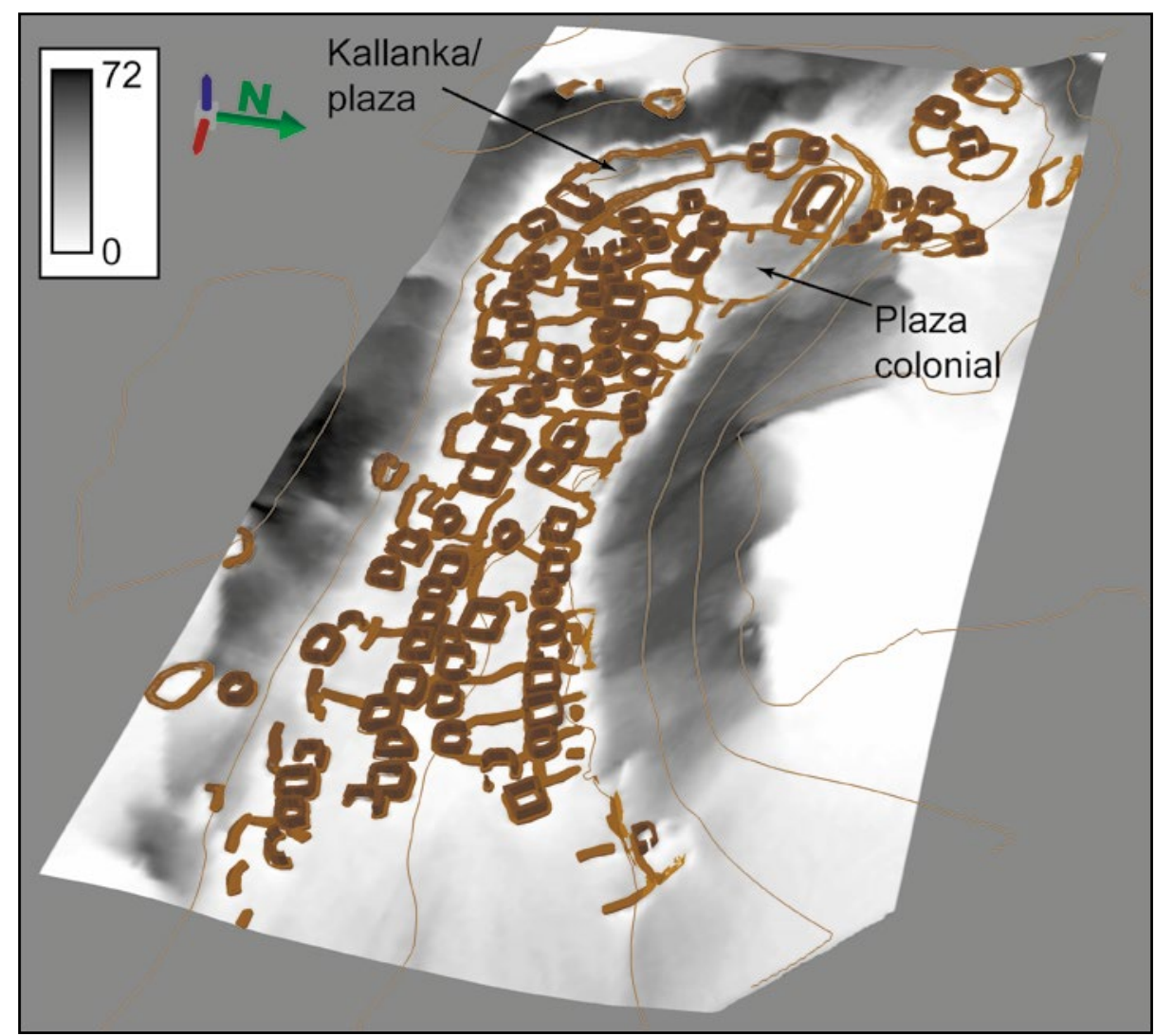

Figura 4. Perspectiva de Malata sobre una superficie de visibilidad cumulativa (viewshed).

en la ubicación de ambos complejos. Los espacios domésticos, por otro lado, son de visibilidad restringida, por lo menos, desde los puntos de vista de observadores en las entradas de sus estructuras.

Alrededor de estos complejos ceremoniales, las zonas residenciales del sitio se dividen entre un núcleo antiguo y periferias de la ocupación colonial temprana (Wernke 2013a, 2013b). Al extremo este del sitio, hay un barrio de estructuras cuadrangulares con rasgos coloniales diagnósticos, que probablemente fue construido por la congregación de población por los franciscanos (Wernke 2013b). La articulación de este «barrio nuevo» con el enfoque ritual colonial — la plaza y la capilla - refuerza la idea de que fue parte de un programa integral. Un análisis de redes espaciales demuestra que, a pesar de su distancia de la plaza colonial en términos cartesianos, dentro del espacio relativo de la red de senderos del sitio, las casas del barrio colonial son cercanas y gozan de acceso más directo por medio de un sendero principal hacia la única entrada a la plaza colonial. Por el contrario, las casas del núcleo antiguo, es decir, las casas que fueron las más céntricas en relación con la kallanka y plaza inkaica, se convirtieron en las más distantes, relativas a la red de caminos hacia la plaza colonial (Wernke 2012).

Otro aspecto importante del patrón de movimiento hacia la plaza colonial y la capilla es que todo el tráfico confluyó frente a la unidad doméstica que identificamos como la casa del kuraka antes de entrar a la plaza. Esta unidad doméstica (compuesta por las estructuras 26, 28 y sus patios asociados) es la excepción al patrón de ubicación de estructuras cuadrangulares por los extremos del sitio. Es decir, cuando había reuniones, procesiones u otras actividades pastorales públicas, todos los participantes habrían desfilado frente a esta unidad doméstica antes de entrar a la plaza. La Estructura 26 es la estructura doméstica más grande del sitio, con atributos arquitectónicos 
coloniales, y una organización interior y conjunto de artefactos que la identifican como la casa de la élite indígena. Se nota, entonces, una clara intención de estructurar una medida de vigilancia por parte de autoridades reconocidas (indígenas) con la intrusiva construcción de esta unidad doméstica a un lado de la plaza colonial (Wernke 2012).

Estas simulaciones de percepción visual y movimiento, en conjunto con los datos sobre la secuencia de construcción y formalización de la doctrina indican cómo los medios arquitectónicos fueron activamente manipulados por los agentes imperiales inkaicos y españoles. Como será evidente, tales procesos no terminaron con la reducción toledana en el valle, sino que parecen íntegros a su emplazamiento y organización espacial.

\section{Mawchu Llacta (la reducción de Santa Cruz de Tute)}

El año 2004, como parte de la misma prospección toponímica que identificó Malata, el autor se encontró con las ruinas de lo que obviamente era una reducción toledana ubicada a 4100 m.s.n.m., a $2 \mathrm{~km}$ lineales al noroeste del pueblo actual de Tuti. La reducción está situada en plena puna, ocupando el fondo de una cuenca amplia. Un bofedal pasa por el centro del sitio (Fig. 5). Ahora conocido simplemente como Mawchu Llacta (también Machu Llacta, Mawka Llacta, y Ñawpa Llacta; es decir, "pueblo viejo») por los pobladores del actual pueblo de Tuti, este sitio fue la reducción toledana original, registrada como «Santa Cruz de Tute [sic], llamado el Espinar» en las visitas de 1591, 1604, y 1615-1617. Fue ocupado hasta mediados del siglo XIX. Correspondencia eclesiástica describe un proceso puntuado de desocupación desde finales del siglo XVIII y una fecha terminal definitiva de 1843 , cuando sus últimos habitantes se reubicaron al actual pueblo de Tuti. Dado su excelente estado de conservación y su historia ocupacional por toda la época colonial hasta las primeras décadas de la época republicana, Mawchu Llacta presenta una oportunidad casi única para estudiar el entorno construido de una reducción, desde su construcción, su uso cotidiano y ceremonial, y su abandono.

El Proyecto Arqueológico Tuti Antiguo ha completado una primera fase de investigación entre 2011 y 2014, enfocado en el levantamiento y prospección arquitectónica, y prospección intensiva en superficie. Mientras que los datos de estas temporadas están todavía en proceso de análisis, aquí se presentan algunas observaciones y hallazgos preliminares.

Las observaciones generales presentadas aquí resaltan los aspectos aparentemente paradójicos de la reducción: su construcción era claramente una tarea de gran envergadura e inversión de mano de obra para su población, y su diseño alteró muchas dimensiones de la vida diaria. Pero a la vez su ubicación y organización fueron significativamente influenciadas por un asentamiento grande e importante de la época inkaica en el mismo local.

Acercando a la reducción desde el valle abajo, el visitante habría subido por un camino formal por una colina pendiente, antes de pasar debajo de un arco de ingreso (las columnas de este arco todavía se mantienen bien conservadas). Desde este arco se abre una vista amplia del poblado. Esta presentación parece diseñada para producir un impacto visual, ya que no es la ruta menos costosa ni intuitiva hacia la reducción. También es impactante porque la reducción no se revela hasta que se pasa por la cresta de la colina debajo del arco. Lo que llama la atención de inmediato es el patrón ortogonal estandarizado de manzanas y calles, y la escala considerable (el trazado urbano se extiende más de 0,5 kilómetros por eje) del asentamiento, así como las grandes extensiones de pastos del bofedal hacia su zona central (Fig. 6).

$\mathrm{Al}$ igual que las otras reducciones en el valle, Mawchu Llacta está organizada en una cuadrícula de bloques cuadrados. Las manzanas son notablemente uniformes en extensión, variando solo entre 40 y 43 metros por eje, lo que corresponde a un «cordel» (el tamaño estipulado por las ordenanzas de Toledo; un cordel equivale 50 «varas»). Es evidente también que la construcción de la red urbana fue el primer paso en la construcción de la reducción, dado que varias manzanas fueron tiradas al cordel y demarcadas con hileras de piedras, pero no copadas con estructuras. Por ejemplo, aparentemente la parte central del sitio nunca fue utilizada como zona habitacional. La construcción se concentra alrededor de un área central cuadriculada pero básicamente vacía. Esta zona corresponde 


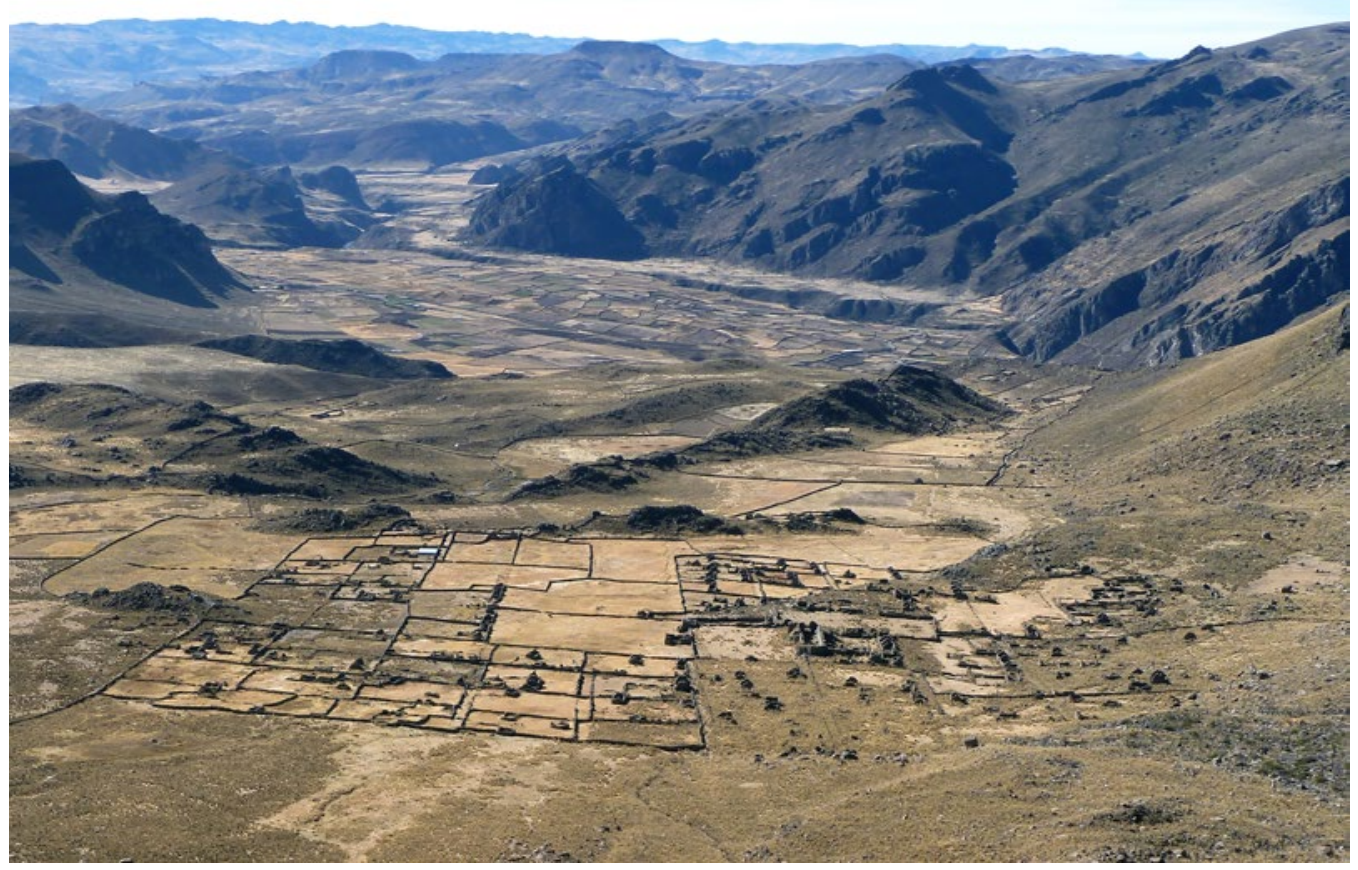

Figura 5. Vista panorámica de Mawchu Llacta, desde el oeste.

al gran bofedal pantanoso que corre por el centro del sitio. Puede parecer extraño que se haya construido una reducción en un pantano, pero el bofedal sin duda proporcionó pastos para los grandes rebaños de camélidos de sus habitantes. Esta área probablemente funcionó como zona de pastoreo comunal, tal vez dividido por bloques de acuerdo a ayllu o parcialidad. En ese sentido, la forma urbana compacta ajena al patrón de asentamiento disperso de la puna no fue impuesta arbitrariamente al paisaje, sino que lo fue de una forma que mitigó las perturbaciones económicas.

De manera similar, parece que la planificación urbana rígida no se extendió a la organización interior de las manzanas o la distribución o las formas de las estructuras internas dentro de ellas. La mirada del estado probablemente no se extendía al diseño específico de los espacios domésticos, a juzgar por la variabilidad de sus orientaciones y disposiciones dentro de las manzanas. En cualquier caso, no se conformó el modelo ideal de Toledo de vigilancia, que especificó que se divida cada manzana en cuatro unidades domésticas, cada una con acceso solo a la calle y no internamente entre sí.

Sin embargo, tampoco había una continuidad simple de diseño o construcción de estructuras domésticas desde la época prehispánica. Un análisis detallado de la arquitectura doméstica no está al alcance de este ensayo, pero cabe señalar que en estas zonas altas de la provincia, las estructuras domésticas de la época prehispánica terminal fueron predominantemente de planta circular, y construidas de forma aglutinada alrededor de patios compartidos (Wernke 2013b). Como vimos para Malata, esta forma de unidad doméstica fue contestada o reemplazada con la congregación de nuevas unidades domésticas en las doctrinas tempranas. Las nuevas unidades domésticas fueron constituidas por casas rectilineares con un patio frontal correspondiente, $y$, a veces, un segundo edificio de servicio asociado. Los grupos arquitectónicos domésticos en Mawchu Llacta, aunque muy variable en general, siguen este modelo post-hispánico. Entonces, parece que ciertas formas arquitectónicas introducidas ya se habían convertido en modelos normativos para el espacio doméstico. Si el estado no impuso un modelo estándar en sí, un nuevo modelo hegemónico del espacio doméstico ya se había afianzado. 


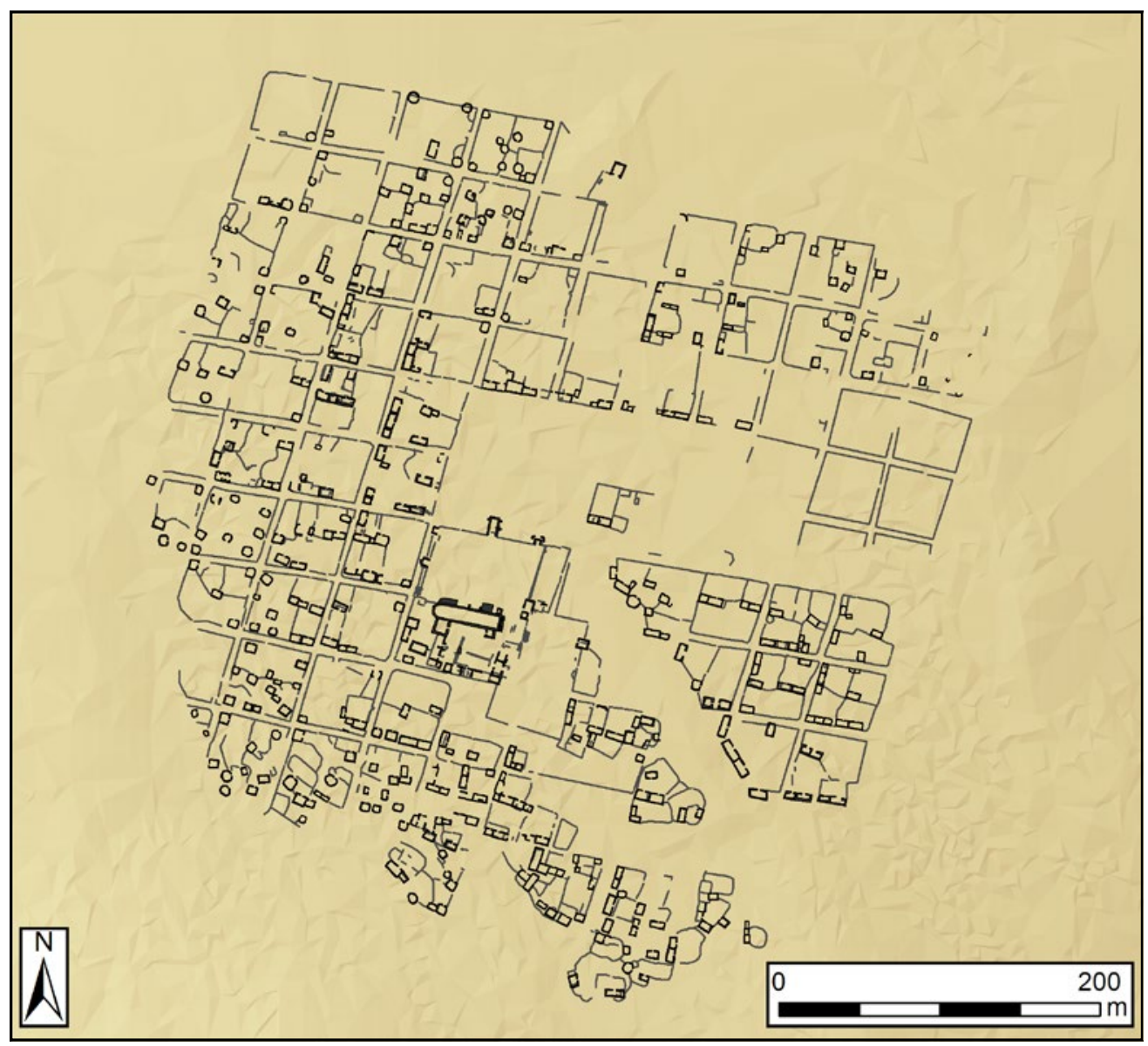

Figura 6. Plano arquitectónico de Mawchu Llacta.

Pasando de nuevo a la escala del sitio en su conjunto, la insistencia en la retícula ortogonal regular es especialmente evidente e impresionante cuando se considera la irregularidad del relieve topográfico, y el hecho de que esta área fue también el lugar de un asentamiento importante durante la época inkaica (Fig. 7). Los restos de este centro inkaico mayor fueron casi - pero no totalmente- obliterados por la reducción, y lo que queda en pie es aún intrigante. Pensando en el patrón ortogonal del sitio, uno se esperaría encontrar el orden más regular de la traza urbana en el centro del sitio, alrededor de la iglesia y la plaza —el lugar de la vida pública y ritual._ - Pero es todo lo contrario, aquí es donde la cuadrícula ortogonal es menos regular (y básicamente el único lugar de incongruencia de la traza ortogonal). Mirando más de cerca a la zona alrededor de la iglesia, hay dos plazas: una situada al lado del portal lateral de la iglesia, y otra frente a la iglesia. Esta segunda plaza frente a la iglesia no se ajusta a la cuadrícula ortogonal ni por sus dimensiones ni su forma: es trapezoidal, no rectangular, como la otra plaza. Esta plaza casi seguramente corresponde a la plaza central del asentamiento inkaico original. Siendo este el caso, la reducción se orientó por el complejo ceremonial central del asentamiento inka.

Otras líneas de evidencia apoyan esta interpretación. Aunque solo recientemente se han completado la recolección intensiva de artefactos, se puede afirmar que hay una marcada concentración de cerámica diagnóstica del Horizonte Tardío en esta zona de la reducción, sugiriendo que era el núcleo del asentamiento anterior. También, se encuentran bloques de andesita finamente trabajados 


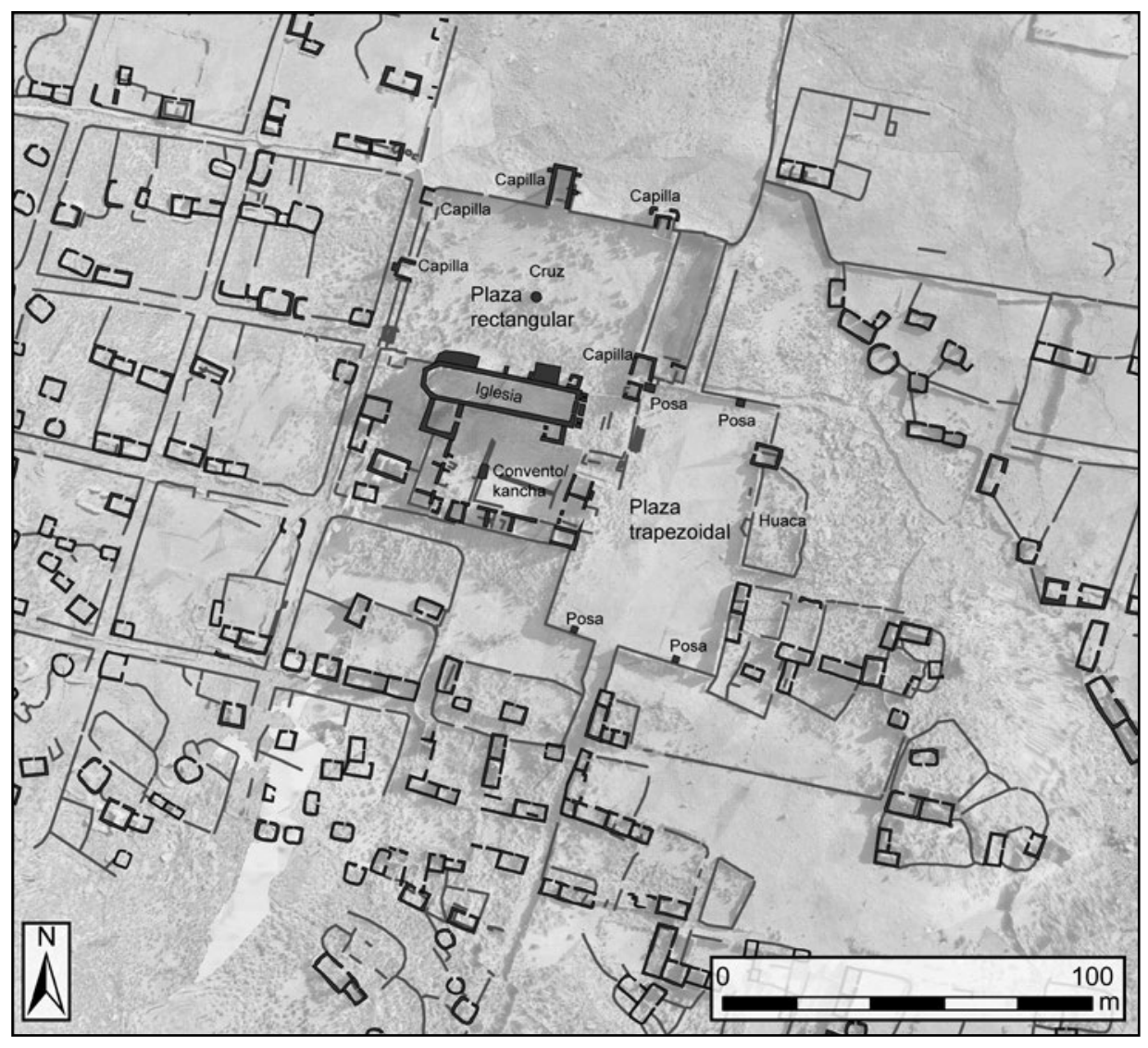

Figura 7. Detalle de la zona central de Mawchu Llacta.

del estilo imperial inkaico exclusivamente en las paredes de la iglesia y el convento (más tarde, la casa cural) (Fig. 8). Esta zona adyacente a la plaza central fue probablemente una kancha, compuesta por edificios de mampostería inkaica. Vale señalar que este tipo de mampostería solo se ha registrado en los tres centros administrativos principales del valle: dos de estos coinciden con las ubicaciones de las reducciones de Yanque y Lari, y el tercero el sitio de Kallimarka, adyacente a Cabanaconde (Doutriaux 2004; Wernke 2006). Al parecer, este sitio tenía una importancia administrativa similar para esta zona alta de la provincia, donde se concentraban los grandes rebaños de camélidos de los collaguas. En tercer lugar, adyacente a la plaza trapezoidal en su lado este (al otro lado del convento) se encuentra una colina amurallada que parece distintiva por los grandes afloramientos de roca madre y rocas grandes de formas inusuales. Se observan restos de terrazas o cercos alrededor de las partes más altas en la zona. También es una de las zonas de más alta concentración de cerámica diagnóstica del Horizonte Tardío. Se sospecha que se trata de una zona ritual: una huaca.

Si esta lectura del espacio central de la reducción es correcta, los rasgos centrales del sitio original son todavía detectables, y su configuración espacial conforman las normas arquitectónicas inkaicas - una huaca, plaza central, y kancha/sector de elite adyacentes. Además, estos elementos centrales juegan con sus contrapartes de la reducción: la plaza fue reutilizada como una de sus dos plazas principales, y la kancha fue convertida en iglesia y convento.

La evidencia de la modificación y uso ritual de estos espacios entrelazados es especialmente interesante. La plaza trapezoidal fue modificada sutilmente para acomodar procesiones católicas con la construcción de cuatro plataformas de posas. Como antes se había mencionado, posas —altares 


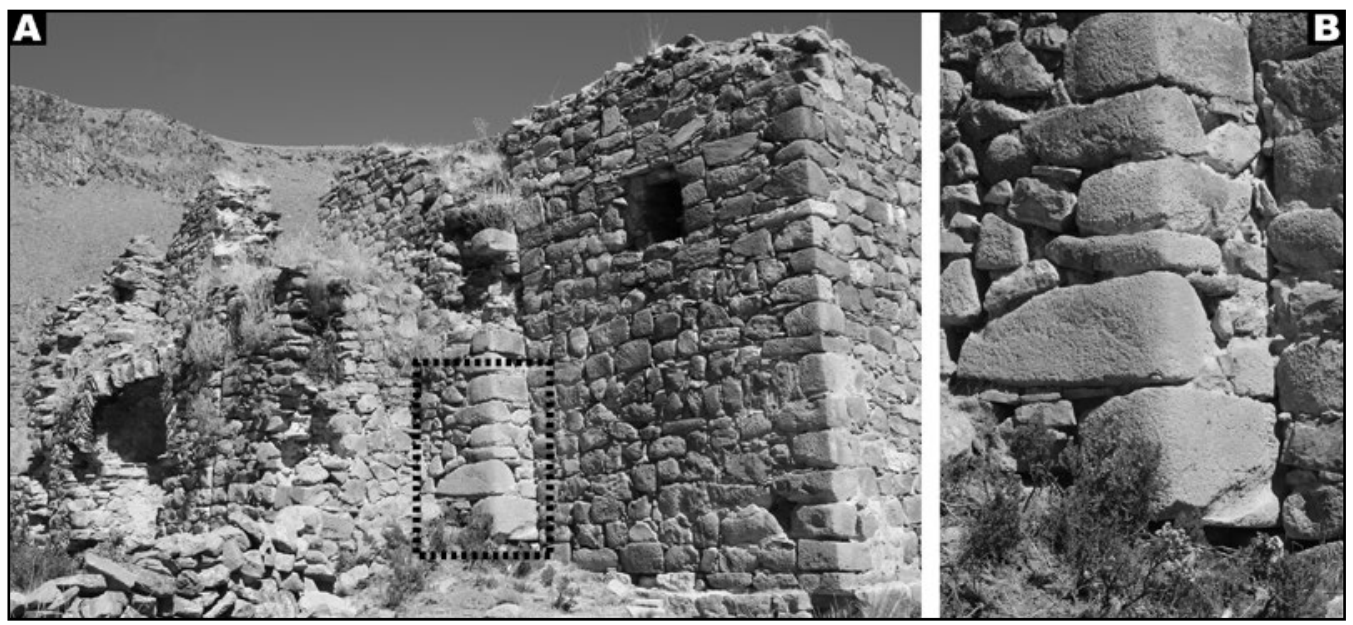

Figura 8. Fachada de la iglesia de Mawchu Llacta (A), con el detalle de bloques finos de estilo inkaico incorporados (B).

o capillas situadas en forma cuadrilateral por el atrio o plaza fueron rasgos estándares de complejos franciscanos desde las misiones tempranas en Mesoamérica. Ya hemos visto la importancia de procesiones por plazas y su prominencia en la evangelización temprana en las doctrinas pretoledanas en el valle del Colca. Siendo el caso que esta plaza trapezoidal corresponde a la plaza central inkaica pre-existente, se trata de un proceso de resonancia y reciclaje espacial similar a lo que ocurrió en las doctrinas, pero en el centro de la misma reducción. Lo más llamativo es la ubicación específica de las pozas: no fueron colocadas en las esquinas del trapezoide, sino de manera que forman un rectángulo entre ellas. Es decir-las pozas «encuadraron el trapezoide» para demarcar un espacio sagrado católico dentro del espacio ceremonial central inkaico. Es otra línea de evidencia de modificación de una plaza preexistente para "convertirla» de prácticas (procesiones, festines, etc.) antes centrales en la producción de obligación entre la población local y el estado inkaico, hacia prácticas centrales en la producción de sujetos cristianos, fieles al catolicismo y el rey español. Mirando más allá de este complejo central, es posible que la orientación de la iglesia hacia esta plaza, y por extensión, toda la traza urbana, fue establecida por lo menos indirectamente por la plaza inkaica.

Otros alineamientos parecen seńalar cómo la reducción fue suspendida en redes de asociaciones y prácticas previas en el paisaje circundante. La otra plaza central- a plaza rectangular orientada longitudinalmente a la iglesia - presenta otro ejemplo intrigante. Si se mira en línea recta desde el portal lateral de la iglesia, la línea de visión intersecta con 1) la peańa de la cruz central en la plaza, 2) la capilla en el centro del lado norte de la plaza, y 3) una capilla situada en la cima de un cerro prominente al extremo norte de la aldea (delimitando el extremo norte, en la mitad del eje esteoeste). Este cerro seguramente tenía una importancia ritual durante la época prehispánica. No se sabe todavía si la traza se alineó con este eje, o si la capilla fue colocada de acuerdo a su alineación con la traza, pero el mismo hecho del alineamiento sugiere que la orientación del sitio y/o esta capilla fue influenciada por rasgos y sitios importantes en el paisaje prehispánico local.

Las plazas centrales de la reducción también sugieren una secuencia de procesos de colonización de espacio semejantes a lo que se ha visto en las doctrinas tempranas: primero una acomodación de prácticas católicas a prácticas y espacios inkaicos analógos hacia un orden espacial más erradicativo con la construcción de una plaza nueva con sus rasgos más ortodoxos. En Mawchu Llacta, la plaza rectangular representa una inversión inmensa en la "perfección» de la práctica católica y la producción de policía. Los mismos elementos presentes en la plaza trapezoidal están presentes en la plaza rectangular, pero en forma mucho más elaborada. En lugar de cuatro plataformas simples para posas, se construyeron cinco capillas y una cruz central. Tres de estas están ubicadas en las esquinas sureste, noreste, y noroeste. La cuarta esquina (suroeste) fue utilizada como la entrada principal a la 
plaza, y por eso parece que no se colocó una capilla allá. La quinta capilla, como antes se ha mencionado, está en el centro del lado norte de la plaza (y se alinea con la cruz central, el portal lateral de la iglesia, y la capilla encima del cerro al extremo norte del sitio). Esta capilla tiene más del doble de tamaño que las otras capillas en la plaza. Es posible que funcionara como capilla de miserere-una configuración que se encuentra en otras reducciones en el valle (como por ejemplo en el caso de la capilla de San Sebastián en Coporaque; ver Tord 1983: 87-89).

Parece bastante evidente, entonces, que la fundación de esta reducción habría sido una imposición inmensa para la población local, pero no fue una imposición arbitraria. Al contrario, fue emplazada y orientada cuidadosamente de acuerdo a antecedentes inkaicos. Los dilemas centrales del reinado colonial y del entorno construido no fueron solucionados, sino amplificados en este contexto local: la dependencia de las prácticas y los rasgos inkaicos y autóctonos es bien evidente. A través de estas combinaciones, el catolicismo y las concepciones coloniales del orden social fueron aprehendidos e incorporados por los habitantes de la reducción. Es decir, el proceso de reducción produjo un orden social nuevo, pero uno que fue a la vez translocal en sus formas externas pero irreductiblemente local en sus significados. Con este resumen breve, se puede empezar de apreciar la simultánea producción y desestabilización del dominio colonial a través del entorno construido en una reducción.

\section{Ordenando edificios, edificando orden}

El intento de generar orden a través del entorno construido parece bastante claro a través del colonialismo inkaico y español, y, como se ha argumentado, la escenificación del espectáculo jugó un rol central en ambas tradiciones y técnicas de gobernabilidad. Las labores considerables expendidas (por las comunidades locales) hacia la creación de estos escenarios — aún en estos contextos alejados de los centros metropolitanos señala su importancia central en el impulso y la política colonial. La remodelación de asentamientos ya existentes por los inkas para crear nodos ceremoniales con las mismas unidades arquitectónicas (kallanka/pata) y su subsecuente remodelación a doctrinas franciscanas (iglesia/plaza) es testigo de un largo proceso de incorporación mutua entre las comunidades locales y estos poderes coloniales. Este proceso no se corta, sino continúa con la reducción toledana: aunque Mawchu Llacta parecería a simple vista un asentamiento impuesto según un modelo europeo, elementos inkaicos de emplazamiento, construcción, y planificación urbana están presentes-no solamente por sus márgenes, sino también en su núcleo y origen de concepción como asentamiento. Como el lector notará, este tipo de reutilización, reciclaje y superposición no es nada inusual ni sorprendente. Muchos ejemplos semejantes saltan a la mente: la reducción de Hatunqolla (construida encima de un centro administrativo inkaico), la iglesia de Santo Domingo en Koricancha en Cuzco, la iglesia de Chincheros, y la iglesia de San Juan Bautista en Huaytará (elaborada a partir de una estructura fina inkaica) solo para nombrar algunos de los ejemplos más espectaculares y conocidos.

Pero estas observaciones no quieren decir que se trata de una arquitectura de conquista, o que las formas construidas producían el orden social que se pretendía, porque ambos dependían de su resonancia con antecedentes comunitarios autóctonos. Los ritos escenificados en las plazas inkaicas céntricas en las aldeas locales se hicieron legibles por la dramaturgia del pacto de la reciprocidad que escenificaron. Las procesiones católicas que se llevaron a cabo en las plazas de las doctrinas y las reducciones - a veces las mismas plazas - se hicieron comprensibles y se incorporaron a través de su resonancia con sus antecedentes inkaicos. Pero a la vez, lo que se sugiere no es un argumento para continuidad o criptopaganismo de parte de los indígenas (es decir, que «realmente» fueron adorando a los deidades de antigüedad), sino que ambos lados del encuentro colonial fueron mutuamente transformados en su articulación. De esta manera, el entorno construido sí habría interpelado a las comunidades locales - y produjo el dominio- pero a la vez se abrió a nuevas posibilidades de contestarlo. 


\section{Agradecimientos}

Este capítulo se originó en una ponencia presentada en el Primer Simposio Internacional de Arqueología Histórica, un evento muy especial y productivo para el desarrollo de la arqueología histórica en los Andes. El autor expresa su gratitud a los organizadores (y los editores del presente volumen). Las investigaciones en Malata fueron financiadas por una beca de la Fundación Nacional de Ciencias (EE.UU.), beca número 0716883. La investigación se realizó bajo la autorización de las resoluciones directorales 0716883 (2006) y 828 (2007) del Instituto Nacional de Cultura del Perú (Mag. Ericka Guerra Santander, codirectora). Las investigaciones en Mawchu Llacta fueron financiadas por una beca interdisciplinaria de la Escuela de Postgrado de la Universidad de Vanderbilt. La investigación se realizó con autorización de las resoluciones directorales 431-012 (Steven A. Wernke, director; Viviana Siveroni, codirectora) y 007-2013-DGPA-VMPCIC-MC (Steven A. Wernke, director; Gabriela Oré Menéndez, codirectora) del Ministerio de Cultura del Perú. Las colaboraciones de Teddy Abel Traslaviña Arias fueron claves para el desarrollo del proyecto. Se agradece los esfuerzos de Gabriela Oré Menéndez y Carla Hernández Garavito en la producción del mapa de base de Mawchu Llacta. El trabajo de campo fue una colaboración con más de 40 estudiantes voluntarios, y se agradece todas sus labores. El Dr. Félix Palacios, director del Museo de Arqueología de la UNSA, prestó su apoyo continuo durante la planificación y ejecución de los proyectos. Se agradece profundamente a la Municipalidad Distrital de Tuti y a la Comisión de Regantes de la Comunidad de Tuti por su apoyo y espíritu de colaboración.

\section{Notas}

${ }^{1}$ En el pasaje original, se indica: «No regime can exist comfortably without providing at least a token semblance of its popularity or at least its entitlement to deference. Relationships that comprise glaring asymmetries in power ever require, it seems, ritual articulation in the presence of an audience; and an audience of political subjects always has the potential to transform, or maybe sometimes actually to reject those relations» (Bell 2006: 5-6).

2 «Los Religiosos [franciscanos] comenzaron sus tareas por Coporaque, en donde de varios ayllos o Parcialidades esparcidas, como la de Cupi, Collana-pataca, Yumasca, Kayaupataca, lograron juntarlos a una sola ranchería. Formaron una Capilla en Cupi, dedicada a San Antonio, y después de años levantaron un Templo formal en Coporaque consagrado a Santiago Apostol» (Echeverría y Morales 1952 [1804]: 80).

\section{REFERENCIAS}

Bell, A.

2006 Spectacular power in the Greek and Roman city, Oxford University Press, New York. https://doi.org/ 10.1093/acprof:oso/9780199242344.001.0001

Benavides, M. A.

1994 The Franciscan church of Yanque (Arequipa) and Andean culture, The Americas 50(3), 419-436. https:// doi.org/10.2307/1007168

Bray, T.

2003 Inca pottery as culinary equipment: Food, feasting, and gender in imperial state design, Latin American Antiquity 14(1), 1-22. https://doi.org/10.2307/972232

Burkhart, L. M.

1991 Encounter of religions: The indigenization of christianity; the Nahua scholar-interpreters, Center for Latin American and Caribbean Studies, Brown University, Providence.

1996 Holy Wednesday: A Nahua drama from Early Colonial Mexico, University of Pennsylvania Press, Philadelphia. 
1998 Pious performances: Christian pageantry and native identity in Early Colonial Mexico, en: E. H. Boone y T. Cummins (eds.), Native traditions in the postconquest world, 361-381, Dumbarton Oaks, Washington, D.C.

Coben, L. S.

2006 Other Cuzcos: Replicated Theaters of Inka Power, en: T. Inomata y L. S. Coben (eds.), Archaeology of performance: Theaters of power, community, and politics, 223-260, Altamira Press, Berkeley.

Cook, N. D.

2002 'Tomando posesión’ Luis Gerónimo de Oré y el retorno de los franciscanos a las doctrinas del valle del Colca, en: J. Flores Espinoza y R. Varón Gabai (eds.), El hombre y los Andes: homenaje a Franklin Pease G.Y., vol. 2., 889-903, Pontificia Universidad Católica del Perú, Lima.

Córdoba y Salinas, D. de

1957 Chrónica franciscana de las provincias del Perú, Academy of American Franciscan History, Washington,

[1651] D.C.

Dillehay, T. D.

2003 El colonialismo inka, el consumo de chicha y los festines desde una perspectiva de banquetes políticos, Boletin de Arqueología PUCP 7, 355-363.

Doutriaux, M.

2004 Imperial conquest in a multiethnic setting: The Inka occupation of the Colca Valley, Peru, tesis de doctorado, Department of Anthropology, University of California, Berkeley.

Durston, A.

2007 Pastoral quechua: The history of christian translation in colonial Peru, 1550-1650, University of Notre Dame Press, Notre Dame.

Echeverría y Morales, F.

1952 Memoria de la santa iglesia de Arequipa, Imprenta Portugal, Arequipa.

[1804]

Estenssoro, J. C.

2001 El simio de Díos: los indígenas y la iglesia frente a la evangelización del Perú, Siglos Xvi-Xvii, Bulletin de l'Institut Francais d'Études Andines 30(3), 455-474. https://doi.org/10.4000/bifea.6956

2003 Del paganismo a la santidad: la incorporación de los indios del Perú al catolicismo, 1532-1750, Intituto Francés de Estudios Andinos/Pontificia Universidad Católica del Perú/Instituto Riva-Agüero, Lima. https://doi.org/10.4000/books.ifea.4412

Galdos Rodríguez, G.

1984 Expansión de los collaguas hacia el valle de Arequipa, El Derecho 296, 81-152.

Gisbert, T. y J. de Mesa

1985 Arquitectura andina, 1530-1830: historia y análisis, Embajada de España en Bolivia, La Paz.

Gose, P.

2008 Invaders as ancestors: On the intercultural making and unmaking of Spanish colonialism in the Andes, University of Toronto Press, Toronto.

Gutiérrez, R., C. Esteras Martín y A. Málaga Medina

1986 El valle del Colca (Arequipa): Cinco siglos de arquitectura y urbanismo, Libros de Hispanoamérica, Buenos Aires.

Kosiba, S. y A. M. Bauer

2012 Mapping the political landscape: Toward a GIS analysis of environmental and social difference, Journal of Archaeological Method and Theory 14(1), 61-101. https://doi.org/10.1007/s10816-011-9126-z

Lara, J.

2004 City, temple, stage: Eschatological architecture and liturgical theatrics in New Spain, University of Notre Dame, Notre Dame.

Makowski, K.

2003 Urbanismo en los Andes prehispánicos, en: il mondo dell' archeologia, vol. I, Instituto de la Enciclopedia Italiana, Roma. 
Málaga Medina, A.

1974 Las reducciones en el Perú (1532-1600), Historia y Cultura 8, 141-172.

1977 Los collagua en la historia de Arequipa en el siglo XVI, en: F. Pease (ed.), Collaguas I, 93-130, Pontificia Universidad Católica del Perú, Lima.

Morris, C.

1970 Huanuco Viejo: An Inca administrative center, American Antiquity 35(3), 344-362.

1973 Establecimientos estatales en el Tawantinsuyu: una estrategia de urbanismo obligado, Revista del Museo Nacional 39, 135-144.

1982 The infrastructure of Inka control in the Peruvian central highlands, en: G. A. Collier, R. Rosaldo y J. D. Wirth (eds.), Inca and Aztec states, 1400-1800: Anthropology and history, 153-171, Academic Press, New York.

2013 El palacio, la plaza y la fiesta en el imperio inca, Pontificia Universidad Católica del Perú, Lima.

Morris, C. y D. E. Thompson

1985 Huánuco Pampa: An Inca City and Its Hinterland, Thames and Hudson, Londres.

Mumford, J. R.

2012 Vertical empire: The general resettlement of Indians in the colonial Andes, Duke University Press, Durham. https://doi.org/10.1215/9780822395591

Pease, F.

1977 Collaguas: una etnía del siglo XVI, en: F. Pease (ed.), Collaguas I, 131-168, Pontificia Universidad Católica del Perú, Lima.

Ramírez, S. E.

2005 To feed and be fed: The cosmological bases of authority and identity in the Andes. Stanford University Press, Stanford.

Schuetz-Miller, M.

2000 Survival of early christian symbolism in monastic churches of New Spain and visions of the millennial kingdom, Journal of the Southwest 42(4), 763-800.

Silverblatt, I.

1988 Imperial dilemmas, the politics of kinship, and Inca reconstructions of History, Comparative Studies in Society and History 30(1), 83-102. https://doi.org/10.1017/s001041750001505x

Tibesar, A.

1953 Franciscan beginnings in Early Colonial Peru, Academy of American Franciscan History, Washington, D.C.

Tord, L. E.

1983 Templos coloniales del Colca-Arequipa, Atlas, Lima.

Toussaint, $\mathrm{M}$.

1967 Colonial art in Mexico [traducción de E. W. Weissmann], University of Texas Press, Austin.

Wernke, S. A.

2006 The politics of community and Inka statecraft in the Colca Valley, Peru, Latin American Antiquity 17(2), 177-208. https://doi.org/10.2307/25063046

2007a Analogy or erasure? Dialectics of religious transformation in the Early Doctrinas of the Colca Valley, Peru, International Journal of Historical Archaeology 11(2), 152-182. https://doi.org/10.1007/s10761007-0027-5

2007b Negotiating community and landscape in the Peruvian Andes: A trans-conquest view, American Anthropologist 109(1), 130-152. https://doi.org/10.1525/aa.2007.109.1.130

2009 La interfaz política-ecológica en el valle del Colca durante la época Inkaica, Andes 7, 587-614.

2011 Convergences: Producing colonial hybridity at an early doctrina in highland Peru, en: M. Liebmann y M. Murphy (eds.), Enduring conquests: Rethinking the archaeology of resistance to Spanish colonialism in the Americas, 77-101, School for Advanced Research, Santa Fe.

2012 Spatial network analysis of a Terminal Prehispanic and Early Colonial settlement in highland Peru, Journal of Archaeological Science 39(4), 1111-1122. https://doi.org/10.1016/j.jas.2011.12.014

2013a Households in transition: Reconstructing domestic organization at an early colonial mission in the Andean highlands, en: M. Oland, S. Hart y L. Frink (eds.), Decolonizing indigenous histories: Exploring prehistoriclcolonial transitions in Archaeology, 77-101, University of Arizona Press, Tucson.

2013b Negotiated settlements: Andean communities and landscapes under Inka and Spanish Colonialism, University Press of Florida, Gainesville. https://doi.org/10.5744/florida/9780813042497.001.0001 